\title{
Risk factors for type 2 diabetes in groups stratified according to metabolic syndrome: a 10-year follow-up of The Tromsø Study
}

\author{
Josepha Joseph $\cdot$ Johan Svartberg • \\ Inger Njølstad $\cdot$ Henrik Schirmer
}

Received: 18 June 2010/ Accepted: 15 December 2010

(c) The Author(s) 2010. This article is published with open access at Springerlink.com

\begin{abstract}
Many incident cases of type 2 diabetes do not fulfil the metabolic syndrome, which accordingly has been questioned both as a research and clinical tool. The aim of this study was to determine differences in risk factors for type 2 diabetes between groups with high or low metabolic score. The study population were 26,093 men and women attending the Troms $\varnothing$ Study in 1994, followed through 2005, and who did not have diabetes when entering the study. A total of 492 incident cases of type 2 diabetes were registered. A metabolic score was defined according to a modified version of the National Cholesterol Education Program Adult Treatment Panel III. For those fulfilling $\geq 3$ metabolic score criteria, increasing age, body mass index (BMI), triglycerides and a family history of diabetes were independent predictors. Age, BMI, and triglycerides predicted type 2 diabetes more strongly in subjects with low metabolic score, whereas high HDL cholesterol was not protective in this low risk group. The risk associated with a positive family history was unaffected by level of metabolic score. In addition smoking, low education and in
\end{abstract}

J. Joseph $(\varangle) \cdot$ I. Njølstad · H. Schirmer

Department of Community Medicine, University of Troms $\varnothing$,

9037 Troms $\varnothing$, Norway

e-mail: josepha.joseph@uit.no

J. Svartberg

Division of Internal Medicine, University Hospital of North

Norway, Troms $\varnothing$, Norway

J. Svartberg

Department of Clinical Medicine, University of Troms $\varnothing$,

Troms $\varnothing$, Norway

H. Schirmer

Department of Cardiology, University Hospital of North

Norway, Troms $\varnothing$, Norway men also physical inactivity were independent risk factors only in those with low metabolic score. Adding these nonmetabolic risk factors increased correct classification from an ROC area of 77.2 to $87.1 \%$ ( $P$ value $<0.0001)$. One half of the incident cases of type 2 diabetes were missed by using high metabolic score for risk prediction.

Keywords Type 2 diabetes $\cdot$ Metabolic syndrome $\cdot$ Low metabolic score · High metabolic score $\cdot$ Non-metabolic risk factors $\cdot$ Receiver operating characteristics

$\begin{array}{ll}\text { Abbreviations } \\ \text { BMI } & \text { Body mass index } \\ \text { BP } & \text { Blood pressure } \\ \text { CVD } & \text { Cardiovascular disease } \\ \text { CI } & \text { Confidence interval } \\ \text { GAD } & \text { Glutamic acid decarboxylase } \\ \text { HbA1c } & \text { Glycated haemoglobin } \\ \text { HR } & \text { Hazard ratio } \\ \text { HDL } & \text { High-density lipoprotein } \\ \text { LTPA } & \text { Leisure-time physical activity } \\ \text { NCEP } & \text { National Cholesterol Education Program } \\ \text { ROC } & \text { Receiver operating characteristics } \\ \text { SD } & \text { Standard deviation }\end{array}$

\section{Introduction}

The concept of metabolic syndrome was introduced to improve identification of risk of cardiovascular disease (CVD) [1], but has failed to improve the detection of cardiovascular risk beyond ordinary risk scores [2]. As a predictor of type 2 diabetes, metabolic syndrome has 
proved more useful [3], but due to the dichotomous use of risk factors that in reality represent a continuum of risk, it has been less useful than scores using multiple levels of risk [4].

According to a joint statement by the American Diabetes Association and the European Association for the Study of Diabetes, it is suggested that health-care providers should avoid labelling patients with the term metabolic syndrome, because this might create the impression that the metabolic syndrome denotes a greater risk than its components, or that it is more serious than other cardiovascular disease risk factors, or that the underlying pathophysiology is clear [5]. Accordingly, a report of WHO experts suggested to drop the concept both for clinical and research purposes [6]. The concept initially intended to generate research hypotheses, has been used for identification of subjects at risk and has thereby probably distracted attention from other risk factors of type 2 diabetes.

The aim of this study was to evaluate the risk factors of type 2 diabetes in groups stratified according to metabolic score and evaluate whether diabetes in subjects with low metabolic score were more likely to be detected by other risk factors.

\section{Materials and methods}

Study design and population

The Troms $\emptyset$ Study is a multipurpose single-centre population based prospective study with repeated health surveys among inhabitants of the Troms $\varnothing$ municipality, Northern Norway [7]. All residents born 1969 or earlier were invited to the fourth Troms $\varnothing$ survey in 1994/95. Altogether 27,158 (77\%) out of an eligible population of 35,420 subjects, participated. Subjects not consenting to medical research ( $n=201$ ), subjects with a prior diagnosis of type 2 diabetes $(n=336)$, unknown type 2 diabetes (45), type 1 diabetes $(n=81)$, uncertain type of diabetes during follow up $(n=91)$, uncertain year of diagnosis $(n=142)$ and subjects with missing values for any metabolic syndrome criteria and other relevant risk factors $(n=169)$, were excluded, leaving 26,093 to be included in this study. Subjects were followed from the date of enrolment (1994/ 95) through December 31st, 2005. The median follow up time was 10.8 years.

A subgroup of 7,160 comprising those aged 55-74 years and 5-10\% of those 25-54 and 75-85 years of age were invited to a second visit a few weeks after the main survey; this gave additional baseline information on waist circumference, non-fasting glucose and HbAlc and the possibility to estimate the prevalence of unknown diabetes. In $2001,7,064$ of the original cohort of the 1994/95 survey participated in the fifth Troms $\varnothing$ survey. This enabled us to evaluate the change in risk factors from 1994 to 2001.

The screening included a self administered questionnaire concerning treatment for hypertension, smoking habits and level of leisure-time physical activity (LTPA). The questionnaire was checked by trained nurses. Physical inactivity was defined as less than $3 \mathrm{~h}$ per week of light activity in leisure time without sweating or dyspnoea. Moderate LTPA was defined as $3 \mathrm{~h}$ or more of light activity or 1-2 $\mathrm{h}$ of hard LTPA which caused sweating or dyspnoea per week. Hard LTPA was defined as hard activity with sweating or becoming out of breath for $3 \mathrm{~h}$ or more per week [8].

Educational level was defined having completed 1: primary and secondary-school, 2: high school or vocational school 1-4 years, 3: university less than 4 years and 4: 4 years or more.

Family history of diabetes was reported as first degree family members, i.e. parents or siblings, with a history of diabetes. Smoking status was ascertained as current, previous or never smoker.

Height and weight were measured at screening with light clothing, and body mass index (BMI) was computed as $\mathrm{kg} / \mathrm{m}^{2}$. Waist circumference was measured in centimetres. Blood pressure was recorded in the sitting position after 2 min' rest by the use of an automatic blood pressure measurement device (Dinamap Vital Signs Monitor, Waukesha, WI, US). Three recordings were taken at 2-min intervals, and the mean of the two last readings were used in this analysis. The participant was considered to have hypertension if he or she had systolic blood pressure $(\mathrm{BP}) \geq 130 \mathrm{mmHg}$ or diastolic $\mathrm{BP} \geq 85 \mathrm{mmHg}$ at screening, or reported being on antihypertensive medication.

Non-fasting blood samples were collected from an antecubital vein, serum prepared by centrifugation after one hour respite at room temperature, and analyzed at the Department of Clinical Chemistry, University Hospital of North Norway. Serum total cholesterol and triglycerides were analyzed by enzymatic colorimetric methods and commercially available kits (CHOD-PAP for cholesterol and GPO-PAP for triglycerides: Boeringer Mannheim). Serum HDL-cholesterol was measured after precipitation of lower-density lipoproteins with heparin and manganese chloride. Determination of glycosylated haemoglobin (HbA1c) in EDTA whole blood was based on an immunoturbidometric assay (UNIMATES, F. Hoffmann-La Roche AG: Basel, Switzerland).

Definition of metabolic score

A metabolic score was defined according to a modified version of the National Cholesterol Education Program 
(NCEP) Adult Treatment Panel III [9], in which the metabolic syndrome is present when three or more of the following criteria are fulfilled.

1. Hypertension; $\mathrm{BP} \geq 130 / 85 \mathrm{mmHg}$ and/or antihypertensive medication.

2. Hypertriglyceridemia; fasting serum triglycerides $>$ $1.70 \mathrm{mmol} / \mathrm{L}$.

3. Low high-density lipoprotein (HDL) cholesterol; below $1.03 \mathrm{mmol} / \mathrm{L}$ in men and $<1.29 \mathrm{mmol} / \mathrm{L}$ in women.

4. Central obesity; waist circumference $>102 \mathrm{~cm}$ (men), $>88 \mathrm{~cm}$ (women).

5. Fasting plasma glucose $\geq 6.1 \mathrm{mmol} / \mathrm{L}$.

Because waist circumference measurements were available only for a subset of participants, BMI was used instead of waist circumferences in the metabolic score, as suggested as a possible alternative in other studies $[10,11]$. In our study, the cut off values for BMI were calculated as the mean BMI values in men and women with waist circumference of 102 and $88 \mathrm{~cm}$, respectively. Accordingly, BMI $>28.3 \mathrm{~kg} / \mathrm{m}^{2}$ for men and $>27.0 \mathrm{~kg} / \mathrm{m}^{2}$ for women were used. The last criterion; fasting plasma glucose was not available and not included in the analysis.

Subjects were given a score from 0 to 4 for each fulfilled feature of the metabolic syndrome (based on the modified NCEP definition) and grouped according to number of fulfilled features. A score of $\geq 3$ fulfilled criteria was labelled "high metabolic score". Conversely, those with 2 or less fulfilled criteria were labelled "low metabolic score".

Follow-up and case identification

Possible cases of diabetes mellitus were identified through self-reported diabetes in questionnaires or HbA1c $>6.5 \%$ in the health surveys 1994/95 or 2001, and through linkage of the Troms $\varnothing$ Study participant list to diabetes related discharge diagnoses in the digital patient records at the only local hospital (ICD- 9 codes 250, 357.2, 362.0, 583.8, 648.0, 648.8, 790.2, ICD-10 codes E10 -E14, O24 and R73). Some cases of hospital confirmed diabetes, but with no diabetes-related discharge diagnosis, were detected through our adjudication process for cardiovascular diseases. We validated all possible cases of diabetes by checking their medical records. Cases were classified as having no diabetes, type 1 or type 2 diabetes, based on glucose measurements if they had non-fasting glucose $\geq 11.1 \mathrm{mmol} / \mathrm{L}$, fasting glucose $>7.0 \mathrm{mmol} / \mathrm{L}, 2 \mathrm{~h}$ glucose $\operatorname{load} \geq 11.1 \mathrm{mmol} / \mathrm{L}$ or $\mathrm{HbA} 1 \mathrm{c} \geq 7.0 \%$ in the hospital laboratory database or recorded use of insulin or oral anti-diabetic drugs [12, 13]. C-peptide measurement was the common method at the hospital during the followup period to differentiate between type 1 and type 2 diabetes, while Glutamic acid decarboxylase antibody (anti-GAD) measurements were performed in a minority of cases. Follow up ended December 31st, 2005.

Study approval

This study has been approved by the Regional Committee for Medical and Health Research Ethics, Northern Norway and all participants included have given written informed consent to scientific use of data and linkage to health registries.

Statistical analysis

Data are presented stratified by gender. Differences in means between groups were tested using age adjusted general linear models. Categorical variables were tested with logistic regression. As cases were diagnosed with diabetes throughout the follow up period, hazard ratios (HR) for diabetes were calculated using Cox proportional hazard models adjusting for age and all the other variables. To evaluate differences in HR estimates between subgroups, interaction terms between risk factor and subgroups were tested. The proportional hazard assumption was examined using log minus log plots and evidence of non-proportionality were not found. Preliminary analyses revealed significant interactions between sex and BMI and between sex and triglycerides. Accordingly, all analyses were sex stratified. ROC areas were computed for presence of high metabolic score univariably, in multivariable analysis with the metabolic syndrome factors as continuous variables, and in a full model with all significant predictors entered in a logistic regression model. Significance tests were two-tailed, and the significance level was chosen at $5 \%$. Estimations of differences between ROC areas were performed in SAS statistical software (SAS Institute, Cary, NC, USA) version 9.2 using the roc and roccontrast statement in proc logistic. All other analyses were performed using SPSS version 17 (Statistical Package for Social Sciences, Chicago, IL, USA, 2009).

\section{Results}

In the total study population aged 25-98 years and without diabetes at baseline ( $n=26,093), 492$ new cases of type 2 diabetes were identified during follow up, 294 in men and 198 in women.

Table 1 shows age adjusted baseline characteristics of those who remained free of diabetes and those who developed type 2 diabetes during follow-up and who were with or without metabolic syndrome at baseline. Of the 26,093 subjects, 3,684 had a high metabolic score, i.e. 
Table 1 Baseline characteristics in men and women initially free from diabetes, by future diabetes and metabolic status

\begin{tabular}{|c|c|c|c|c|c|c|}
\hline \multirow[t]{3}{*}{ Variables } & \multicolumn{3}{|l|}{ Men } & \multicolumn{3}{|l|}{ Women } \\
\hline & \multirow{2}{*}{$\begin{array}{l}\text { Non } \\
\text { diabetics } \\
(n=12,104)\end{array}$} & \multicolumn{2}{|c|}{$\begin{array}{l}\text { New cases of type } 2 \text { diabetes } \\
(n=294)\end{array}$} & \multirow{2}{*}{$\begin{array}{l}\text { Non } \\
\text { diabetics } \\
(n=13,497)\end{array}$} & \multicolumn{2}{|c|}{$\begin{array}{l}\text { New cases of type } 2 \text { diabetes } \\
(n=198)\end{array}$} \\
\hline & & $\begin{array}{l}\text { Low metabolic } \\
\text { score }(n=157)\end{array}$ & $\begin{array}{l}\text { High metabolic } \\
\text { score }(n=137)\end{array}$ & & $\begin{array}{l}\text { Low metabolic } \\
\text { score }(n=76)\end{array}$ & $\begin{array}{l}\text { High metabolic } \\
\text { score }(n=122)\end{array}$ \\
\hline Age (years) & $46.1 \pm 0.13$ & $58.1 \pm 0.85^{* * *}$ & $54.1 \pm 0.89 * * *^{\dagger}$ & $46.5 \pm 0.13$ & $59.1 \pm 1.59 * * *$ & $57.6 \pm 1.02 * * * \dagger$ \\
\hline Systolic blood pressure $(\mathrm{mmHg})$ & $137 \pm 0.15$ & $145 \pm 1.55$ & $153 \pm 1.62 * * * *^{\dagger}$ & $131 \pm 0.18$ & $146 \pm 2.67$ & $158 \pm 2.14^{* * * *^{\dagger}}$ \\
\hline Diastolic blood pressure $(\mathrm{mmHg})$ & $79.7 \pm 0.11$ & $86.1 \pm 0.94$ & $91 \pm 1.11^{* * * \dagger}$ & $76.1 \pm 0.11$ & $82.5 \pm 1.54$ & $87.3 \pm 1.69 * * * \dagger$ \\
\hline BMI $\left(\mathrm{kg} / \mathrm{m}^{2}\right)$ & $25.5 \pm 0.03$ & $27.5 \pm 0.31 * * *$ & $30.8 \pm 0.28 * * * *^{\dagger}$ & $24.6 \pm 0.03$ & $27.2 \pm 0.57 * * *$ & $31.3 \pm 0.45 * * * \dagger$ \\
\hline Total cholesterol (mmol/l) & $6.03 \pm 0.01$ & $6.5 \pm 0.09$ & $6.7 \pm 0.09 * * *$ & $5.94 \pm 0.12$ & $6.65 \pm 0.14$ & $6.86 \pm 0.11 * *$ \\
\hline HDL cholesterol (mmol/l) & $1.35 \pm 0.02$ & $1.35 \pm 0.02$ & $1.07 \pm 0.21 * * *^{\dagger}$ & $1.64 \pm 0.01$ & $1.69 \pm 0.04$ & $1.24 \pm 0.03 * * * \dagger$ \\
\hline Triglycerides (mmol/l) & $1.75 \pm 0.01$ & $1.82 \pm 0.09^{*}$ & $3.42 \pm 0.18^{* * * \dagger}$ & $1.31 \pm 0.01$ & $1.46 \pm 0.07 *$ & $2.81 \pm 0.11 * * * \dagger$ \\
\hline $\begin{array}{l}\text { Positive family history } \\
\text { of diabetes } n(\%)\end{array}$ & $1,372(11.3)$ & $39(24.8) * * *$ & $32(23.4)^{* * *}$ & $1,804(13.4)$ & $25(32.9)^{* * *}$ & $39(31.7)^{* * *}$ \\
\hline \multicolumn{7}{|l|}{ Anti-hypertensive treatment $n(\%)$} \\
\hline Current & $658(5.4)$ & $25(15.9)^{*}$ & $40(29.2)^{* * * *^{\dagger}}$ & $743(5.5)$ & $11(14.5)^{*}$ & $29(23.7)^{* * * \dagger}$ \\
\hline Previous & $268(2.3)$ & $6(3.8)$ & $2(1.5)$ & $358(2.7)$ & $5(6.6)$ & $13(10.7)^{* *}$ \\
\hline Never & $11,178(92.3)$ & $126(80.3)$ & $95(69.3)$ & $12,396(91.8)$ & $60(78.9)$ & $80(65.6)$ \\
\hline \multicolumn{7}{|l|}{ Education $n(\%)$} \\
\hline Primary/secondary & $5,961(49.2)$ & $94(59.9)^{*}$ & $73(53.3)$ & $6,546(48.5)$ & $48(63.2)^{*}$ & $72(59.0)$ \\
\hline High school & $1,526(12.7)$ & $18(11.5)$ & $21(15.3)$ & $2,301(17.1)$ & $10(13.2)$ & $15(12.3)$ \\
\hline College/university $<4$ years & $2,256(18.6)$ & $21(13.4)$ & $20(14.6)$ & $2,489(18.4)$ & $10(13.2)$ & $17(13.9)$ \\
\hline College/university $\geq 4$ years & $2,361(19.5)$ & $24(15.2)$ & $23(16.8)$ & $2,161(16.0)$ & $8(10.4)$ & $18(14.8)$ \\
\hline \multicolumn{7}{|c|}{ Leisure-time physical activity level $n(\%)$} \\
\hline Hard & $1,828(15.1)$ & $16(10.2)$ & 16 (11.7) & 1,998 (14.8) & $6(7.9)$ & $15(12.3)$ \\
\hline Moderate & $6,781(56.0)$ & $53(33.7)$ & $70(51.1)$ & $6,305(46.7)$ & $19(25.0)$ & 35 (28.7) \\
\hline Inactive & $3,495(28.9)$ & $88(56.1)^{* *}$ & $51(37.2)$ & $5,194(38.5)$ & $51(67.1)^{*}$ & $72(59.0)$ \\
\hline \multicolumn{7}{|l|}{ Daily smoking $n(\%)$} \\
\hline Current & 4,593 (37.9) & $92(58.6) * * *$ & 65 (47.4) & $5,027(37.2)$ & $39(51.3)^{* * *}$ & $45(36.9)$ \\
\hline Previous & $3,756(31.1)$ & $40(25.5)$ & $40(29.2)$ & 2,944 (21.8) & $13(17.1)$ & 19 (15.6) \\
\hline Never & $3,755(31.0)$ & $25(15.9)$ & $32(23.4)$ & $5,526(41.0)$ & $24(31.6)$ & $58(47.5)$ \\
\hline
\end{tabular}

The Troms $\varnothing$ Study 1994-2005

Values are means \pm standard error or $n$ (percentage)

Low metabolic score: $<3$ metabolic syndrome criteria fulfilled

High metabolic score: $\geq 3$ metabolic syndrome criteria fulfilled (metabolic syndrome)

$B M I$ Body mass index, HDL cholesterol high density lipoprotein cholesterol

$* P<0.05, * * P<0.01, * * * P<0.0001$, age adjusted in analysis of covariance for continuous variables and logistic regression for categorical variables comparing non-diabetics with either low or high metabolic score

${ }^{\dagger} P$ for differences between low and high metabolic score, obtained by age adjusted analysis of covariance or logistic regression where appropriate

fulfilled at least 3 of the metabolic syndrome criteria; $16 \%$ (95\% CI $15-17 \%)$ in men and $13 \%(95 \%$ CI $12-14 \%)$ in women. As shown, only $53 \%$ of incident cases of type 2 diabetes had a high metabolic score at baseline (47\% of men and $62 \%$ of women). Those with a low metabolic score were more likely to be older, less educated and more inactive and smoke more than the other two groups. Otherwise, the low score group had a mean BMI, triglycerides and antihypertensive treatment significantly higher than those not developing diabetes, and significantly lower than the high score group.

For those fulfilling $\geq 3$ metabolic syndrome criteria, age, BMI, triglycerides, and a family history of diabetes were independent predictors of diabetes (Table 2). Of these risk factors age, BMI, and triglycerides predicted type 2 diabetes more strongly in subjects with low metabolic score. HDL cholesterol showed a protective effect only in women with a high metabolic score. The risk associated 
Table 2 Risk factors for type 2 diabetes by low and high metabolic score

\begin{tabular}{|c|c|c|c|c|c|c|}
\hline \multirow[t]{2}{*}{ Variables } & \multicolumn{3}{|l|}{ Men (294 cases) } & \multicolumn{3}{|c|}{ Women (198 cases) } \\
\hline & $\begin{array}{l}\text { Low metabolic } \\
\text { score } \\
\text { HR }(95 \% \text { CI }) \\
n=10,426\end{array}$ & $\begin{array}{l}\text { High metabolic } \\
\text { score } \\
\text { HR }(95 \% \text { CI }) \\
n=1,972\end{array}$ & $\begin{array}{l}P \text { value for } \\
\text { difference in } \\
\text { HR between } \\
\text { groups }\end{array}$ & $\begin{array}{l}\text { Low metabolic } \\
\text { score } \\
\text { HR }(95 \% \text { CI }) \\
n=11,983\end{array}$ & $\begin{array}{l}\text { High metabolic } \\
\text { score } \\
\text { HR }(95 \% \text { CI }) \\
n=1,712\end{array}$ & $\begin{array}{l}P \text { value for } \\
\text { difference in } \\
\text { HR between } \\
\text { groups }\end{array}$ \\
\hline Cases of type 2 diabetes $(n)$ & 157 & 137 & & 76 & 122 & \\
\hline Age (10 years) & $1.76(1.64,2.11)$ & $1.54(1.36,1.79)$ & 0.000 & $1.54(1.82,1.8)$ & $1.29(1.12,1.48)$ & 0.003 \\
\hline BMI (1SD) & $2.28(1.98,2.75)$ & $1.59(1.38,1.84)$ & 0.000 & $1.68(1.40,2.01)$ & $1.52(1.30,1.78)$ & 0.007 \\
\hline Triglycerides (1SD) & $1.36(1.14,1.64)$ & $1.16(1.09,1.23)$ & 0.000 & $1.34(1.07,1.68)$ & $1.17(1.04,1.32)$ & 0.000 \\
\hline HDL cholesterol (1SD) & $1.02(0.76,1.12)$ & $1.01(0.78,1.14)$ & - & $1.06(0.82,1.36)$ & $0.75(0.58,0.97)$ & 0.000 \\
\hline Hypertension (yes) & $1.47(1.01,2,15)$ & $0.69(0.35,1.41)$ & 0.001 & $1.86(1.05,3.30)$ & $1.53(0.69,3.42)$ & 0.004 \\
\hline Family history (yes) & $2.19(1.51,3.16)$ & $2.07(1.40,2.98)$ & - & $2.54(1.57,4.12)$ & $2.25(1.55,3.26)$ & - \\
\hline \multicolumn{7}{|l|}{ Education } \\
\hline College/university $\geq 4$ years & 1.00 & 1.00 & - & 1.00 & 1.00 & - \\
\hline College/university $<4$ years & $0.95(0.53,1.72)$ & $1.01(0.61,2.02)$ & & $1.11(0.43,2.83)$ & $0.84(0.45,1.75)$ & \\
\hline High school & $1.07(0.59,2.01)$ & $1.11(0.61,2.01)$ & & $1.22(0.47,3.12)$ & $0.89(0.49,1.87)$ & \\
\hline primary and secondary & $1.81(1.19,2.88)$ & $1.53(0.77,1.96)$ & & $1.75(1.09,4.57)$ & $1.04(0.69,1.98)$ & \\
\hline \multicolumn{7}{|l|}{ Leisure-time physical activity } \\
\hline Hard & 1.00 & 1.00 & - & 1.00 & 1.00 & - \\
\hline Moderate & $0.81(0.47,1.39)$ & $0.98(0.57,1.70)$ & & $0.91(0.38,2.10)$ & $0.43(0.34,1.22)$ & \\
\hline Inactive & $1.94(1.18,3.36)$ & $1.10(0.57,1.79)$ & & $1.70(0.91,4.33)$ & $0.48(0.38,1.28)$ & \\
\hline \multicolumn{7}{|l|}{ Smoking } \\
\hline Never & 1.00 & 1.00 & - & 1.00 & 1.00 & - \\
\hline Previous & $0.70(0.42,1.17)$ & $0.61(0.38,1.22)$ & & $1.10(0.56,2.07)$ & $0.76(0.45,1.28)$ & \\
\hline Current & $1.68(1.23,4.25)$ & $1.33(0.91,2.14)$ & & $1.56(1.18,4.18)$ & $1.41(0.89,2.47)$ & \\
\hline
\end{tabular}

The Troms $\varnothing$ Study 1994-2005

Cox' proportional hazard regression analysis, multivariably adjusted

Low metabolic score: less than 3 metabolic score criteria fulfilled

High score: 3 or more metabolic score criteria fulfilled

For dichotomous variables; HR are given for answering 'yes' with 'no' as reference

For continuous variables; HR is given for a SD change in the variable

$B M I$ Body mass index, $C I$ confidence interval, $H D L$ high density lipoprotein, $H R$ hazard ratio, $S D$ standard deviation

Differences in HR between groups were determined using interaction terms between variable and group

with a positive family history was unaffected by metabolic score. In addition hypertension, smoking, low education and in men also inactivity, were independent risk factors only in those with a low metabolic score. Adding these non metabolic risk factors increased correct classification significantly (ROC area increased from 77.2 to $87.1 \%$; $P$ value $<0.0001)$.

The risk of type 2 diabetes increased by increasing number of fulfilled components of the metabolic score (Fig. 1). The absolute risk of developing type 2 diabetes over 10.8 years increased from $0.5 \%$ in men and $0.1 \%$ in women to 9.2 and $9.8 \%$, in those fulfilling zero to 4 metabolic score criteria, respectively. The age adjusted HR for highest metabolic score compared to lowest metabolic score were 16 (95\% CI 8.6-31) for men and 52 (95\% CI
23-119) for women. Adjusting for other risk factors such as smoking, physical inactivity, education and a family history of diabetes did not attenuate the point estimates of risk in men, but the HR in women was reduced to 45 (95\% CI, 20-102). Although identifying a high risk group, our dichotomized metabolic score definition only identified $53 \%$ of cases (ROC area $69.8 \%$ (95\%CI 67.5-72.0\%), whereas a model using the same risk factors as continuous variables correctly classified $81.5 \%$ (95\%CI 79.7-83.3\%). Adding age, gender, inactivity, low education, a positive family history and smoking increased correct classification to an ROC area of $86.7 \%$ (95\%CI 85.5-88.2), both differences $P$ values $<0.0001$.

A sub-group of the total cohort who participated in the 1994 survey $(n=7160)$ were invited to a second screening 


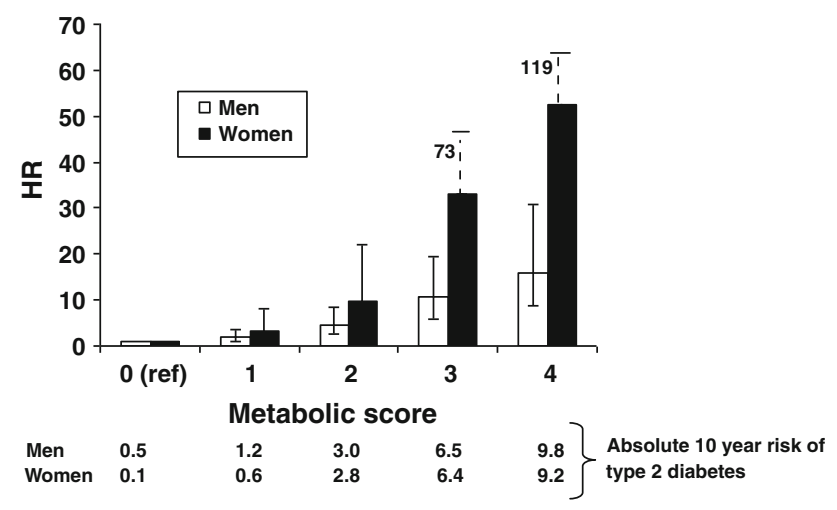

Fig. 1 Age adjusted HR of type 2 diabetes for increasing metabolic score with 95\% confidence intervals. The Troms $\emptyset$ Study 1994-2005. The absolute 10 -year risk of type 2 diabetes (\%) is presented in the table underneath

a few weeks later. In this subgroup 93 subjects reported diabetes in the questionnaire at baseline. In addition we detected 45 subjects with unknown diabetes as detected by $\mathrm{HbA} 1 \mathrm{c} \geq 7.0 \%$ in 1994 . Of these 45 , two had non-fasting glucose $>11.0 \mathrm{mmol} / \mathrm{L}$. The 45 with unknown type 2 diabetes constituted $33 \%$ of a total of 138 with type 2 diabetes at baseline. One of these was detected by our hospital validation.

Those attending this second phase were invited to a new screening in 2001. Of those with a low metabolic score at baseline and who developed type 2 diabetes after 2001, $97 \%$ had changed unfavourably in one or more risk factors before developing type 2 diabetes, but only $36 \%$ had an unfavourable change in 3 or more factors, resulting in $35 \%$ (95\% CI 33-37\%) being reclassified to a high metabolic score before the detection of type 2 diabetes. Of the low score group who did not develop diabetes, 91\% (95\% CI 90-92\%) changed unfavourably in one or more risk factors, but only $11 \%(95 \%$ CI $7-15 \%)$ changed to the high score group during follow up.

\section{Discussion}

Our study shows how the "metabolic syndrome", used as a dichotomously defined exposure variable_although identifying a high risk group, misses half of the incident cases of type 2 diabetes. We found a significantly better detection of cases by adding a family history of type 2 diabetes, smoking, low education and physical inactivity to the risk assessment especially among those with a low metabolic score.

Our study showed an increasing risk of type 2 diabetes with increasing number of metabolic features in accordance with other prospective studies where the relationship between similar features of metabolic syndrome and type 2 diabetes have been analysed [10, 14, 15]. In accordance with other studies, we also found that the use of dichotomous risk factors gave significantly weaker prediction of incident cases of type 2 diabetes than using the metabolic risk factors as continuous variables [4, 15]. Our study strongly indicates a continuous risk associated with all metabolic syndrome features, also below established cut-off values for metabolic syndrome. That those who do not fulfil the criteria at baseline are older, and consequently could have worsened in metabolic profile more slowly, might indicate a need for longer exposure time for those with lower risk factor levels. In both men and women, low risk subjects were significantly older when they developed diabetes compared to high risk subjects. In particular, this was shown for women who had significantly longer follow up time as compared to men before development of diabetes if low in metabolic score. A difference in susceptibility to changes in BMI could be the cause of these observed gender differences. It has been shown that men are more susceptible to an increase in blood pressure given an increase in BMI than are women [16]. Changes in risk factors have been shown to be independent predictors of diabetes risk [17]. Accordingly, we also found worsening of metabolic risk factors in $97 \%$ of low risk subjects who subsequently developed type 2 diabetes.

Furthermore our study strongly indicates that life style risk factors such as physical inactivity, smoking, educational level and also family history of diabetes should be included when assessing diabetes risk. A recent review of tools for predicting risk of type 2 diabetes in daily practice, concluded that the Finnish Diabetes Risk Score (FINDRISC) which included all these risk factors except educational level, showed the highest ROC area (ROC 87\%) compared to metabolic syndrome which had only an ROC of $83 \%$ [18]. Similarly our study showed that adding these non-metabolic risk factors increased correct classification significantly to a similar ROC (87\%). Studies with a multifactorial approach to diabetes risk assessment conclude that the concept of metabolic syndrome has a limited practical utility as a diagnostic or management tool in case of diabetes or CVD [6, 19].

As metabolic syndrome factors are differently distributed among men and women, we find that HDL cholesterol is a protective factor only among women with a high metabolic score, although earlier studies have shown a significant lowering of risk for increasing HDL cholesterol in both men and women [8]. We have earlier shown that this is due to an interaction between HDL cholesterol, BMI and triglycerides most pronounced in women where the protective effect of HDL increased by increasing triglyceride levels and more so at high BMI levels corresponding to the high score group as defined in the present article. This indicates that the definition of a metabolic syndrome does not describe a unified syndrome as such, but a complex of related risk factors. 
Our finding of hypertension being an independent risk factor for type 2 diabetes only in those with a low metabolic score, does not indicate a lack of risk of type 2 diabetes in the high risk group, only that this risk is better identified through increasing levels of the other risk factors age, BMI, triglycerides, smoking and a positive family history of type 2 diabetes. Most of those high risk individuals had elevated blood pressure as shown in Table 1. Our findings indicate that the degree of elevation does not carry an independent risk within this subgroup.

\section{Strengths and limitations}

The study was conducted in a general population and included a large number of men and women with a wide age range at baseline and had a long follow-up. The verification process of diabetes cases was thorough, and included the use of questionnaires, hospital records, and laboratory reports. In addition, the case verification has been conducted at the only hospital in this region.

The limitation of this study is a lack of a baseline screening for diabetes, i.e.; by fasting plasma glucose or oral glucose tolerance test. The use of hospital records to adjudicate type 2 diabetes might further introduce a bias, as subjects with well controlled diabetes detected and attended by their general practitioner only, would be missed. As the hospital laboratory serves also the general practitioners of Troms $\varnothing$, a proportion of those patients would be identified through HbAlc measurements recorded in the hospital database, but many general practitioners have their own $\mathrm{HbAlc}$ kit. In the subgroup of 7,160 participants with $\mathrm{HbAlc}$ and non-fasting glucose measured in a second phase of the baseline screening, there were 45 subjects with unknown type 2 diabetes not detected by our validation. This constitutes $33 \%$ of all with diabetes at baseline. Including $\mathrm{HbAlc}$ measurements at baseline to define prevalent diabetes, increased the yield of unknown diabetes substantially from $23 \%$ in a previous study in our population using only $\mathrm{HbAlc}$ registered at the hospital [17]. Among those 19,495 Troms $\varnothing 4$ participants who did not take part in the second phase of the screening in 1994, there were 246 probable cases of prevalent type 2 diabetes. Given the same prevalence of unknown diabetes in this younger population we probably had 116 undetected cases of diabetes at baseline weakening our chance of finding associations. As the control group is so large it is unlikely that these undetected cases have increased our chance of false positive results.

We used BMI as a proxy of waist circumference as a modified metabolic syndrome criterion, similar to other studies $[10,11]$. To check the validity of this proxy we compared the predictive power of BMI and waist circumference in the sub- population with both BMI and waist circumference measured. For one SD increase in BMI, the HR for type 2 diabetes were 2.20 (95\% CI 1.92-2.52) in men and 1.94 (95\% CI 1.72-2.18) in women. For waist circumference, HR was 2.45 (95\% CI 2.11-2.85) in men and 2.25 (95\% CI 1.96-2.59) in women, respectively. In analysis of ROC the area under curve were for the BMI model 0.73 (95\% CI 0.68-0.77) and for the waist circumference model 0.74 (95\% CI $0.70-0.78)$ in men, and $0.76(95 \% \mathrm{CI}$ $0.71-0.81$ ) and 0.77 (95\% CI $0.74-0.82$ ) in women, respectively. Our study does not support a significant difference in predicting ability between waist circumference and BMI. Some data show that waist circumference predicts diabetes marginally better than BMI [20, 21], whereas other data have shown the opposite [22]. Moreover, BMI and waist circumference have been compared as determinants of metabolic syndrome [23]. Interestingly, these studies found the same cut-off values for BMI corresponding to the established NCEP waist circumference criteria as our study, and they also did not find waist circumference to be superior in predicting diabetes or CVD $[10,11]$.

To test the impact of non-fasting triglyceride measurements, we re-analysed our data using a cut off value of $\geq 2.28 \mathrm{mmol} / \mathrm{L}$ as used in other studies, acknowledging non-fasting values being $20-30 \%$ higher than fasting levels $[10,24]$. The change of triglyceride cut-off did not alter our results significantly.

Fasting glucose was not measured at baseline in our study, and consequently could not be included as the fifth component of the metabolic syndrome. This could possibly attenuate our prediction of risk estimates. But studies which included all 5 characteristics have shown that the 5th criterion identified only an additional $1.2-2.9 \%$ of the metabolic syndrome cases [23, 25]. Accordingly, it is unlikely that the lack of fasting glucose affected validity.

In conclusion, half the incident cases of type 2 diabetes in our study were missed by using a high metabolic score for identification. In the low risk group with a low metabolic score, smoking, low level of education and in men also physical inactivity, significantly improved identification. This opens for targeted prevention of type 2 diabetes for larger groups of the population at risk.

Acknowledgments This research was supported by grants from the Centre for International Health and the support given by the Department of Community Medicine, both at the University of Troms $\varnothing$, Norway. Associate professor Tom Wilsgaard gave important statistical advice. The health surveys in 1994 and 2001 were conducted by the University of Troms $\varnothing$ in collaboration with The National Health Screening Service. The abstract was presented at the Norwegian Conference in Epidemiology, on November 6th, 2009.

Open Access This article is distributed under the terms of the Creative Commons Attribution Noncommercial License which permits any noncommercial use, distribution, and reproduction in any medium, provided the original author(s) and source are credited. 


\section{References}

1. Reaven GM. Banting lecture 1988. Role of insulin resistance in human disease. Diabetes. 1988;37:1595-607.

2. Ford ES. Risks for all-cause mortality, cardiovascular disease, and diabetes associated with the metabolic syndrome: a summary of the evidence. Diabetes Care. 2005;28:1769-78.

3. Ford ES, Li C, Sattar N. Metabolic syndrome and incident diabetes. Diabetes Care. 2008;31:1898-904.

4. Sattar N, McConnachie A, Shaper AG, Blauw GJ, Buckley BM, de Craen AJ, et al. Can metabolic syndrome usefully predict cardiovascular disease and diabetes? Outcome data from two prospective studies. Lancet. 2008;37:1927-35.

5. Kahn R, Buse J, Ferrannini E, Stern M. The metabolic syndrome: time for critical appraisal. Joint statement from the American Diabetes Association and the European Association for the Study of Diabetes. Diabetologia. 2005;48:1684-99.

6. Simmons RK, Alberti KG, Gale EA, Colagiuri S, Tuomilehto J, Qiao Q, et al. The metabolic syndrome: useful concept or clinical tool? Report of a WHO Expert Consultation. Diabetologia. 2010; 53:600-5.

7. Schirmer H, Lunde P, Rasmussen K. Prevalence of left ventricular hypertrophy in a general population; The Tromso Study. Eur Heart J. 1999;20:429-38.

8. Joseph J, Svartberg J, Njølstad I, Schirmer H. Incidence of and risk factors for type-2 diabetes in a general population: The Troms $\emptyset$ Study. Scand J Public Health. 2010;38:768-75.

9. Expert Panel on Detection, Evaluation and Treatment of High blood Cholsterol in Adults. Executive Summary of The Third Report of the National Cholesterol Education Program (NCEP) Expert Panel on Detection, Evaluation, and Treatment of High Blood Cholesterol In Adults (Adults Treatment Pannel III). JAMA. 2001; 285:2486-97.

10. Wannamethee SG, Shaper AG, Lennon L, Morris RW. Metabolic syndrome vs Framingham Risk Score for prediction of coronary heart disease, stroke, and type 2 diabetes mellitus. Arch Intern Med. 2005;165:2644-50.

11. Sattar N, Gaw A, Scherbakova O, Ford I, O'Reilly DS, Haffner $\mathrm{SM}$, et al. Metabolic syndrome with and without C-reactive protein as a predictor of coronary heart disease and diabetes in the West of Scotland Coronary Prevention Study. Circulation. 2003; 108:414-9.

12. Alberti K, Zimmet P, for a WHO consultation. Definition, diagnosis and classification of diabetes mellitus and its complications. Part 1: Diagnosis and classification of diabetes mellitus. Geneva: World Health Organization; 1999.
13. Saudek CD, Herman WH, Sacks DB, Bergenstal RM, Edelman D, Davidson MB. A new look at screening and diagnosing diabetes mellitus. J Clin Endocrinol Metab. 2008;93:2447-53.

14. Wilson PW, D'Agostino RB, Parise H, Sullivan L, Meigs JB. Metabolic syndrome as a precursor of cardiovascular disease and type 2 diabetes mellitus. Circulation. 2005;112:3066-72.

15. Ford ES, Schulze MB, Pischon T, Bergmann MM, Joost HG, Boeing $\mathrm{H}$. Metabolic syndrome and risk of incident diabetes: findings from the European Prospective Investigation into Cancer and Nutrition-Potsdam Study. Cardiovasc Diabetol. 2008;7:35.

16. Wilsgaard T, Schirmer H, Arnesen E. Impact of body weight on blood pressure with a focus on sex differences: the Tromso Study, 1986-1995. Arch Intern Med. 2000;160:2847-53.

17. Jacobsen BK, Bonaa KH, Njolstad I. Cardiovascular risk factors, change in risk factors over 7 years, and the risk of clinical diabetes mellitus type 2. The Tromso study. J Clin Epidemiol. 2002;55:647-53.

18. Schwarz PE, Li J, Lindstrom J, Tuomilehto J. Tools for predicting the risk of type 2 diabetes in daily practice. Horm Metab Res. 2009;41:86-97.

19. Sattar N. Why metabolic syndrome criteria have not made prime time: a view from the clinic. Int J Obes. 2008;32:S30-4.

20. Stevens J, Couper D, Pankow J, Folsom AR, Duncan BB, Nieto FJ, et al. Sensitivity and specificity of anthropometrics for the prediction of diabetes in a biracial cohort. Obes Res. 2001;9: 696-705.

21. Wei M, Gaskill SP, Haffner SM, Stern MP. Waist circumference as the best predictor of noninsulin dependent diabetes mellitus (NIDDM) compared to body mass index, waist/hip ratio and other anthropometric measurements in Mexican Americans-a 7-year prospective study. Obes Res. 1997;5:16-23.

22. Han TS, Williams K, Sattar N, Hunt KJ, Lean ME, Haffner SM. Analysis of obesity and hyperinsulinemia in the development of metabolic syndrome: San Antonio Heart Study. Obes Res. 2002; 10:923-31.

23. Ridker PM, Buring JE, Cook NR, Rifai N. C-reactive protein, the metabolic syndrome, and risk of incident cardiovascular events: an 8-year follow-up of 14719 initially healthy American women. Circulation. 2003;107:391-7.

24. Eberly LE, Stamler J, Neaton JD. Relation of triglyceride levels, fasting and nonfasting, to fatal and nonfatal coronary heart disease. Arch Intern Med. 2003;163:1077-83.

25. Ford ES, Giles WH, Dietz WH. Prevalence of the metabolic syndrome among US adults: findings from the third National Health and Nutrition Examination Survey. JAMA. 2002;287:356-9. 